\title{
An experimental investigation on attentional interference by threatening fixations of the neck in patients with chronic whiplash syndrome
}

\author{
Citation for published version (APA):
}

Vangronsveld, K. L. H., Van Damme, S., Peters, M., Vlaeyen, J. W. S., Goossens, M. E. J. B., \& Crombez, G. (2007). An experimental investigation on attentional interference by threatening fixations of the neck in patients with chronic whiplash syndrome. Pain, 127(1-2), 121-128. https://doi.org/10.1016/j.pain.2006.08.010

Document status and date:

Published: 01/01/2007

DOI:

10.1016/j.pain.2006.08.010

Document Version:

Publisher's PDF, also known as Version of record

\section{Document license:}

Taverne

Please check the document version of this publication:

- A submitted manuscript is the version of the article upon submission and before peer-review. There can be important differences between the submitted version and the official published version of record.

People interested in the research are advised to contact the author for the final version of the publication, or visit the DOI to the publisher's website.

- The final author version and the galley proof are versions of the publication after peer review.

- The final published version features the final layout of the paper including the volume, issue and page numbers.

Link to publication

\footnotetext{
General rights rights.

- You may freely distribute the URL identifying the publication in the public portal. please follow below link for the End User Agreement:

www.umlib.nl/taverne-license

Take down policy

If you believe that this document breaches copyright please contact us at:

repository@maastrichtuniversity.nl

providing details and we will investigate your claim.
}

Copyright and moral rights for the publications made accessible in the public portal are retained by the authors and/or other copyright owners and it is a condition of accessing publications that users recognise and abide by the legal requirements associated with these

- Users may download and print one copy of any publication from the public portal for the purpose of private study or research.

- You may not further distribute the material or use it for any profit-making activity or commercial gain

If the publication is distributed under the terms of Article $25 \mathrm{fa}$ of the Dutch Copyright Act, indicated by the "Taverne" license above, 


\title{
An experimental investigation on attentional interference by threatening fixations of the neck in patients with chronic whiplash syndrome
}

\author{
Karoline Vangronsveld ${ }^{\mathrm{a}, *}$, Stefaan Van Damme ${ }^{\mathrm{b}}$, Madelon Peters ${ }^{\mathrm{a}}$, \\ Johan Vlaeyen ${ }^{a}$, Mariëlle Goossens ${ }^{\mathrm{a}}$, Geert Crombez ${ }^{\mathrm{b}}$ \\ ${ }^{a}$ Department of Medical, Clinical and Experimental Psychology, Maastricht University, P.O. Box 616, 6200 MD Maastricht, The Netherlands \\ ${ }^{\mathrm{b}}$ Department of Experimental, Clinical and Health Psychology, Ghent University, Belgium
}

Received 6 February 2006; received in revised form 24 July 2006; accepted 7 August 2006

\begin{abstract}
Previous studies using a primary task procedure have demonstrated that an experimental pain stimulus interrupts ongoing task performance in healthy volunteers and patients, and that this interruption is intensified by catastrophic thinking about pain and the perceived threat value of the pain stimulus. However, no studies have investigated the interruption of attention by relevant threatening stimuli in specific patient samples. In the present study, 40 patients with chronic whiplash syndrome and 40 healthy controls performed a primary task while simultaneously a potentially threatening neck fixation (i.e., extension and rotation) was imposed. Pain catastrophizing, fear of movement/(re)injury, hypervigilance, and depression were assessed. The patients showed a more pronounced deterioration of performance compared to controls when the neck rotation and extension fixations were introduced. Within the groups, neither catastrophic thinking nor fear predicted the magnitude of the performance deterioration.
\end{abstract}

(C) 2006 International Association for the Study of Pain. Published by Elsevier B.V. All rights reserved.

Keywords: Pain; Whiplash; Catastrophizing; Fear of movement; Attentional interference

\section{Introduction}

Psychosocial factors, such as pain catastrophizing and pain-related fear, have been found to be important in the exacerbation and maintenance of chronic low back pain problems (Vlaeyen et al., 1995a,b; Vlaeyen and Linton, 2000). Few studies have explored the role of these variables in other pain syndromes. For example, it is plausible that these variables are also of value in

\footnotetext{
* Corresponding author. Tel.: +31 43388 1613; fax: +31 43388 4155.

E-mail address: k.vangronsveld@dmkep.unimaas.nl (K. Vangronsveld).
}

patients with chronic neck pain after a motor vehicle accident. Indeed, some of these patients report high levels of pain catastrophizing and pain-related fear (Nederhand et al., 2004). Accordingly, it is reasonable to assume that similar psychosocial mechanisms as in chronic low back pain apply. In this study, we explore one of these mechanisms, i.e. attention.

When pain is interpreted as a physical threat, it demands attention and interrupts ongoing activities. This is a normal mechanism related to the activation of a primitive defensive system that urges escape from somatic threat (Eccleston and Crombez, 1999). However, when pain is chronic and no immediate cure is available, patients may become overalert for pain and its cues, resulting in a persistent disruption of 
attention and behavior. Such overalertness, or "hypervigilance," emerges when patients experience intense pain, have catastrophic thoughts about pain, and become fearful of pain (Goubert et al., 2004; Crombez et al., 2005).

Studies investigating the variables that are implicated in (hyper)vigilance have most often used a primary task paradigm (Crombez et al., 1994; Eccleston, 1994), in which participants are instructed to perform an attention-demanding task (e.g., differentiating two different tones) while experiencing pain (e.g., an electrocutaneous stimulus). A decrease in task performance during pain is considered a measure for the attentional interruption by pain. Interference by pain has been demonstrated in both healthy volunteers and pain patients (Crombez et al., 1996, 1998a, 1999, 2002). Attentional interruption has been found to be amplified by (1) the novelty of pain (Crombez et al., 1994), (2), the threat of intense pain (Crombez et al., 1998a), (3) increased somatic awareness (Eccleston et al., 1997), (4) pain-related fear (Crombez et al., 1999) and (5) pain catastrophizing (Crombez et al., 1998b; Peters et al., 2000, 2002; Vancleef and Peters, 2006).

In the current experiment, we investigated attentional disruption in patients with chronic whiplash syndrome using the primary task paradigm. We used (potentially) noxious stimuli with particular relevance to this patient group. Pilot testing with several movements indicated that especially rotating and extending the neck is considered threatening by these patients. Therefore, as a threatening stimulus we used fixations of the neck in a rotated or extended position during task performance. We hypothesized that patients would show stronger interference of task performance during neck fixations than healthy controls. We also expected that within the patient group, high pain catastrophizing and high pain-related fear would be associated with stronger interference.

\section{Method}

\subsection{Participants}

Forty chronic whiplash patients who responded to an advertisement in a journal of the Dutch and Belgian Whiplash patients' associations and 40 healthy control persons who were recruited from a list of volunteers completed the experiment. The groups were matched for sex and age $(65 \%$ females, in both groups; mean age of the control group 47 years, $[\mathrm{SD}=11.2]$; mean age of the patient group 47 years, $[\mathrm{SD}=11.0]$ ). Patients had complaints of neck pain after a motor vehicle accident for a minimum of 6 months (mean $=6.7$ years, SD =3.4). 57.5 percent of the controls had a paid job of more than $20 \mathrm{~h}$ a week, compared to 47.5 percent in the patient group. All participants gave informed consent and were free to terminate the experiment at any time.

\subsection{Questionnaires}

\subsubsection{Disability}

The Dutch version of the Neck Disability Index (NDI) consists of 10 items concerning functional activities, pain intensity, concentration and headache. The 10 items are scored 0 (no activity limitations) to 5 (major activity limitations) and summed to yield a total score. The NDI is a valid and reliable instrument, sensitive to measure changes within a population of neck pain patients (Vernon, 1997; Helmerson Ackelman and Lindgren, 2002).

\subsubsection{Pain catastrophizing}

Participants completed the Dutch version of the Pain Catastrophizing Scale (PCS; Sullivan et al., 1995). Respondents are asked to reflect on past painful experiences and to indicate the degree to which they experienced each of the 13 thoughts or feelings during pain on a five point scale from 0 (not at all) to 4 (all the time). The Dutch version of the PCS has been shown to be valid and reliable (Van Damme et al., 2002a).

\subsubsection{Fear of movement/(re) injury}

The Dutch version of the Tampa Scale for Kinesiophobia (TSK: Miller et al., 1991) was used to measure fear of movement/(re)injury. The 17 items are scored on a four point scale from "I do not agree at all" (1) to "I absolutely agree" (4). The scale has a good internal consistency and a good test - retest reliability (Swinkels-Meewisse et al., 2003; Roelofs et al., 2004).

\subsubsection{Attention to pain}

The Dutch version of the Pain Vigilance and Awareness Questionnaire (PVAQ; McCracken, 1997) is a 16 item scale used to measure attention to pain. Subjects are instructed to think back to their pain experiences in the last two weeks and rate the frequency with which they attended to pain from 0 (never) to 5 (always). The Dutch version of the PVAQ has good internal consistency and good construct validity (McWilliams and Asmundson, 2001; Roelofs et al., 2003).

\subsubsection{Depression}

The Center for Epidemiological Studies Depression Scale (CES-D; Radloff, 1977) consists of 20 items to measure different dimensions of depression. Questions are rated on a four point scale (0-3). The Dutch version of the CES-D has a good internal consistency and a very good sensitivity and specificity (Beekman et al., 1994).

\subsubsection{Manipulation check}

Pain was assessed using visual analog scales (VAS) consisting of a $100 \mathrm{~mm}$ horizontal line anchored with two labels "no pain at all" on the left side and with "worst pain ever" on the right side (Price et al., 1983). For the threat value and the unpleasantness of the fixations VASs were used with the anchors "not at all threatening" and "extremely threatening" and "not at all unpleasant" and "extremely unpleasant". 


\subsection{Primary task}

The primary task paradigm was programmed and presented by the E-prime software package (Psychology Software Tools, Inc., 2002) on an AMD Athlon 500 Mhz computer with a $85 \mathrm{~Hz}, 17$-in. color monitor. E-prime measures response times with millisecond accuracy.

The frequencies of the tones were adopted from previous experimental studies (Crombez et al., 1996, 1998b, 1999). High $(1000 \mathrm{~Hz})$ and low $(250 \mathrm{~Hz})$ pitch tones $(200 \mathrm{~ms}$ duration) were emitted by the speakers of the computer. Participants responded with two fingers by pressing the left or the right button on a response box. Which button (left or right) corresponded to which tone (high or low) was counter-balanced. Tones were randomized via E-prime with the restriction that no more than three consecutive trials consisted of a tone with the same pitch. The task was presented five times (see below) with each phase consisting of 54 trials. There was no fixed inter-trial interval. Participants had to press a button on the response box to generate the next tone.

\subsection{Procedure}

The experiment was approved by the Medical Ethical Committee of the University Hospital Maastricht. Participants were tested individually in a sound attenuated room designed for psychophysiological experiments. Participants gave informed consent. At the start of the experiment participants were asked to rate their current pain on a VAS. Participants were then seated in front of a computer to perform the task. All instructions were presented on the computer screen. Participants were instructed to respond to the high and low tones as quickly as possible without sacrificing accuracy.

The auditory discrimination task was performed during five phases.

Baseline phase 1: participants completed the tone task without any distraction.

Rotation phase: participants performed the tone discrimination task while the head was fixated in a rotated position. More specifically, participants wore a regular somi-brace with thorax-fixating neck collars, which was adapted for this experiment with a flexible and removable chinrest (see Fig. 1). The head was rotated and fixated at $45^{\circ}$ to the side that participants themselves indicated as their "worst" side, or in the case there was no worst side, to the left.

Baseline phase 2: the brace was removed and participants only performed the tone discrimination task.

Extension phase: participants performed the tone discrimination task while the head was fixated in an extended position. This time participants had to extend their head as far as possible, while their chin was placed on the chinrest.

Baseline phase 3: the brace was removed and participants again performed only the tone discrimination task.

Manipulation check: immediately after baseline phase 3, participants rated to what extent they found the rotation and the extension of the head threatening, painful and unpleasant on the VAS scale. Finally, at the end of the experiment participants rated again their current pain.

Each phase lasted 5-6 min, depending on the patients' speed. Between each phase there was a short period of a few minutes of rest in which the brace was attached or removed and in which patients received the new instruction.

\subsection{Statistical analyses}

Analyses were conducted with the Statistical Package for the Social Sciences version 11.0 (SPSS Inc., 444N. Wacker Drive, Chicago, IL, 60606, USA). The main analyses used repeated measures analysis of variance (ANOVA) with phase as the within-subjects factor and group as the between-subjects factor.

\section{Results}

\subsection{Self-report data}

Patients reported significantly higher scores than controls for neck pain disability, pain catastrophizing, fear of movement/(re)injury, attention to pain and depression. Table 1 presents an overview. Though patients showed elevated scores on the CES-D, they cannot be considered clinically depressed. As expected, patients rated both fixations (rotation and extension of the neck)

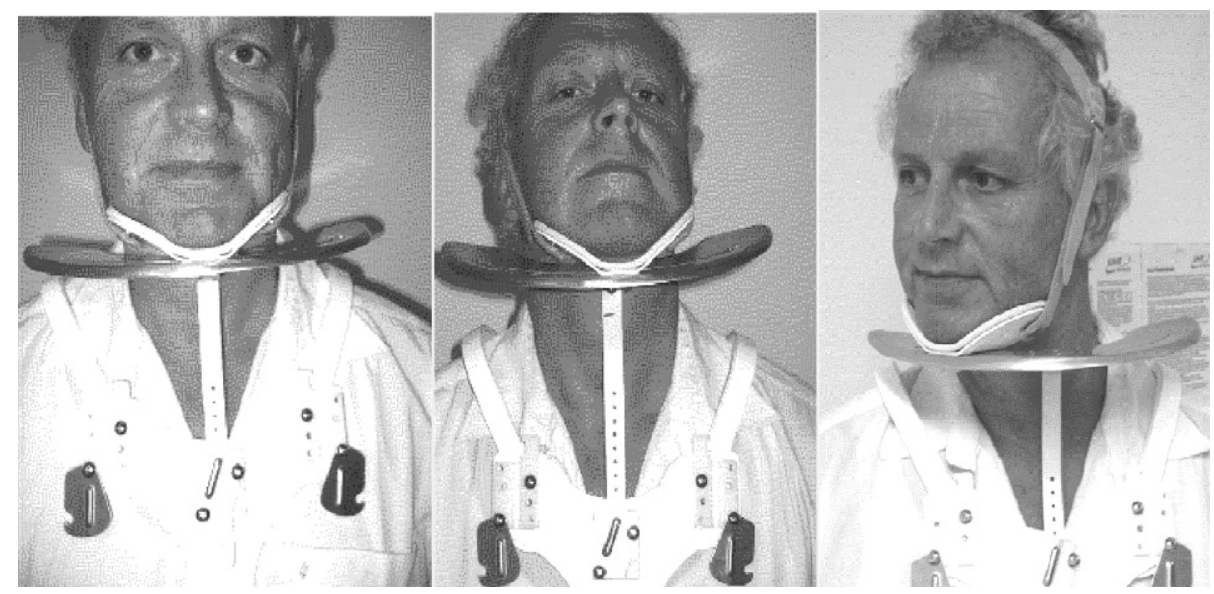

Fig. 1. The modified somi-brace. The chin can rest on a modified chinrest and can be fixated in a rotated and extended position. 
Table 1

Summary scores of questionnaires, VAS-scales of fixations and interference indexes: mean scores, standard deviations, and Independent samples $t$-test

\begin{tabular}{|c|c|c|c|c|}
\hline & Controls mean (SD) & Patients mean (SD) & $t(\mathrm{df})$ & Sig. (two-tailed) \\
\hline NDI & $3.83(5.38)$ & $23.87(7.68)$ & $-13.53(78)$ & $<.001$ \\
\hline TSK & $31.08(6.25)$ & $36.63(6.77)$ & $-3.59(78)$ & $<.001$ \\
\hline PCS & $9.10(9.04)$ & $15.08(10.72)$ & $-2.70(78)$ & .009 \\
\hline PVAQ & $27.78(12.09)$ & $33.57(9.29)$ & $-2.41(78)$ & .019 \\
\hline CES-D & $15.70(6.78)$ & $19.05(6.44)$ & $-2.27(78)$ & .026 \\
\hline Baseline PAIN & $7.30(14.59)$ & $48.85(23.23)$ & $-9.58(78)$ & $<.001$ \\
\hline PAIN after exeperiment & $3.38(11.78)$ & $51.03(25.46)$ & $-10.74(78)$ & $<.001$ \\
\hline Rotation: threat & $10.20(19.62)$ & $43.10(29.04)$ & $-5.94(78)$ & $<.001$ \\
\hline Rotation: pain & $6.75(14.68)$ & $46.28(27.23)$ & $-8.08(78)$ & $<.001$ \\
\hline Rotation: unpleasantness & $18.88(27.95)$ & $54.68(27.03)$ & $-5.82(78)$ & $<.001$ \\
\hline Extension: threat & $16.55(23.56)$ & $62.13(30.0)$ & $-7.52(78)$ & $<.001$ \\
\hline Extension: pain & $10.30(18.16)$ & $64.28(25.32)$ & $-10.91(78)$ & $<.001$ \\
\hline Extension: unpleasantness & $30.28(32.65)$ & $72.67(27.53)$ & $-6.23(78)$ & $<.001$ \\
\hline$\Delta \mathrm{RT} 2-\mathrm{RT} 1$ & $7.53(60.98)$ & 93.15 (166.77) & $-3.05(78)$ & .003 \\
\hline$\Delta \mathrm{RT} 4-\mathrm{RT} 3$ & $7.23(44.88)$ & $95.42(187.32)$ & $-2.90(78)$ & .005 \\
\hline
\end{tabular}

NDI, Neck Disablity Index; TSK, Tampa Scale for kinesiofobia; PCS, Pain Catastrophizing Scale; PVAQ= Pain Vigilance and Awareness Questionnaire; $\Delta \mathrm{RT} 2-\mathrm{RT} 1=$ reaction time rotation phase - reaction time baseline $1, \Delta \mathrm{RT} 4-\mathrm{RT} 3=$ reaction time extension phase - reaction time baseline 3 .

as more threatening, more painful and more unpleasant than controls (Table 1).

\subsection{Primary task data}

For the analyses of the reaction times (RTs), the first 10 trials of each phase were considered familiarization trials and were therefore removed from statistical analyses. Within-subjects, outliers in the RT data were also removed (range: individual mean $\mathrm{RT} \pm 2$ individual SD) (Ratcliff, 1993). Fig. 2 shows the mean response times (RT) per phase for each group.

A 2 (group: control, patient) $\times 5$ (phase: baseline 1 , rotation, baseline 2, extension, baseline 3) ANOVA with repeated measures showed that there was a main effect for group $(F(1,78)=38.60, \quad p<0.001)$. Patients $(M=766 \mathrm{~ms}, \mathrm{SD}=285)$ were overall slower than controls $(M=472 \mathrm{~ms}, \mathrm{SD}=91)$. There was also a main effect for phase, $(F(4,75)=4.91, p=0.001)$ which was further qualified by a phase $\times$ group interaction, $(F(4,75)=4.05, p=0.005)$. Repeated contrasts showed

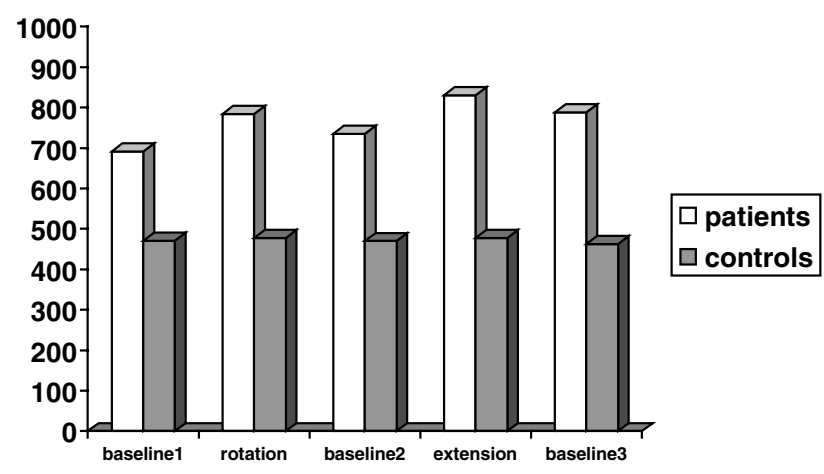

Fig. 2. Mean RTs per phase for each group. that the phase $\times$ group interaction reached significance for the baseline 1 to rotation phase contrast $(F(1,78)=9.3, p=0.003)$ and for the baseline 2 to extension phase contrast $(F(1,78)=8.38, p=0.005)$. Whereas patients showed increased RTs during both threat conditions compared to the previous baseline condition, controls did not show this delay. Simple first contrasts showed that patients did return to baseline in baseline $2(F(1,78)=1.77, p=0.188)$, but in baseline 3 there was still a significant increase in RTs compared to phase $1(F(1,78)=6.66, p=0.012)$.

\subsection{Moderation and mediation}

Performance decrements were further analyzed by computing the differences in RTs for the two experimental phases minus baseline RT (RT rotation phase - RT baseline 1, RT extension phase - RT baseline 2) (see Table 1). To test whether the delayed RTs were related to pain-related fear or pain catastrophizing, either in the whole group or specifically in patients, both interference indexes were subjected to hierarchical regression analyses with the factor group and total scores on the TSK and PCS as predictor variables in step 1, and the interactions between group $\times$ TSK and group $\times$ PCS as predictor variables in step 2 . All variables met the assumption of homogeneity of variance. Only a significant effect of group was found. Pain-related fear nor pain catastrophizing contributed to the delay in RTs during rotation or extension. There were no significant interaction effects (see Table 2).

Finally, we tested whether the delay in RTs was mediated by perceived threat or perceived painfulness of the rotation or extension. We tested mediation according to the guidelines by Baron and Kenny 
Table 2

Linear regression model

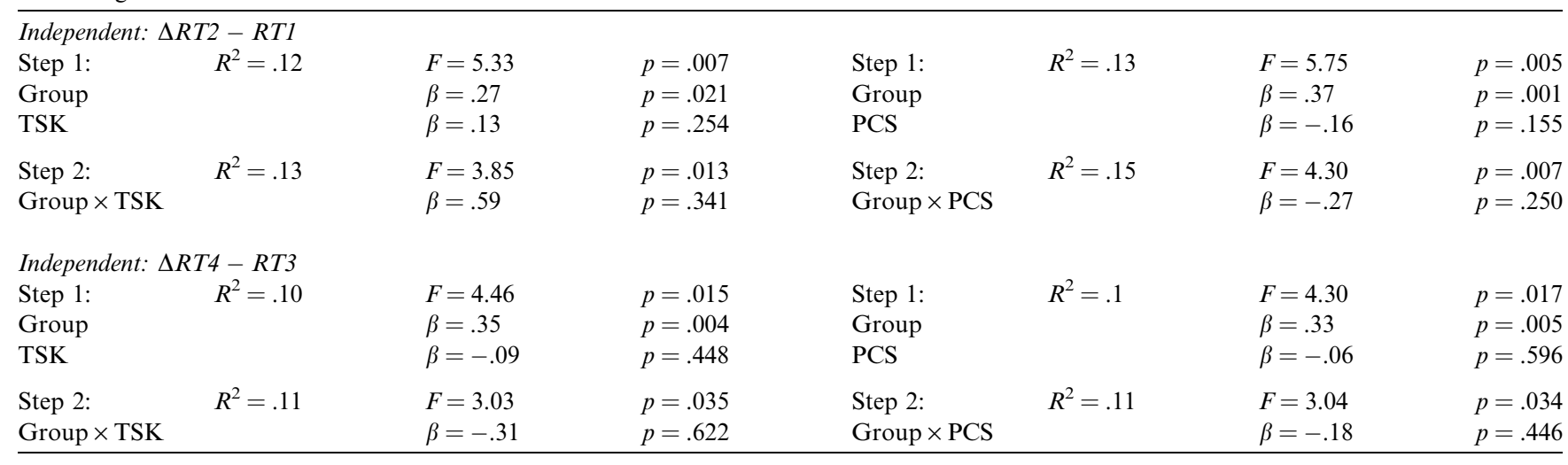

(1986). We used dummy variables $(0=$ control, $1=$ patient) for group identity. Group was a significant predictor of the delay in RTs as well as of the perceived threat and perceived pain during rotation and extension. However, as illustrated in Fig. 3, when group and perceived threat or perceived pain were simultaneously entered into the model as predictors of delayed RTs, the factor group remained the most prominent predictor. We repeated analyses with the factors group and pain increase (baseline pain - pain after experiment), but these analyses did not give evidence for mediation either. Thus the delay in RTs in the patient group does not seem to be mediated by their increased perception of threat or pain during fixations or by pain increase.

\section{Discussion}

The present study examined attentional interference by (potentially) noxious stimuli in patients with chronic whiplash syndrome and healthy controls. Fixation of the head and neck in either an extended or rotated position was used as noxious stimulation with particular relevance for patients with chronic whiplash syndrome. Patients showed performance decrements on a simple auditory reaction time task during neck fixations, whereas controls did not show interference by these fixations. The only significant predictor of performance decrement was group membership (being a patient or a healthy control). Individual differences in pain-related fear and catastrophizing nor perceived painfulness or
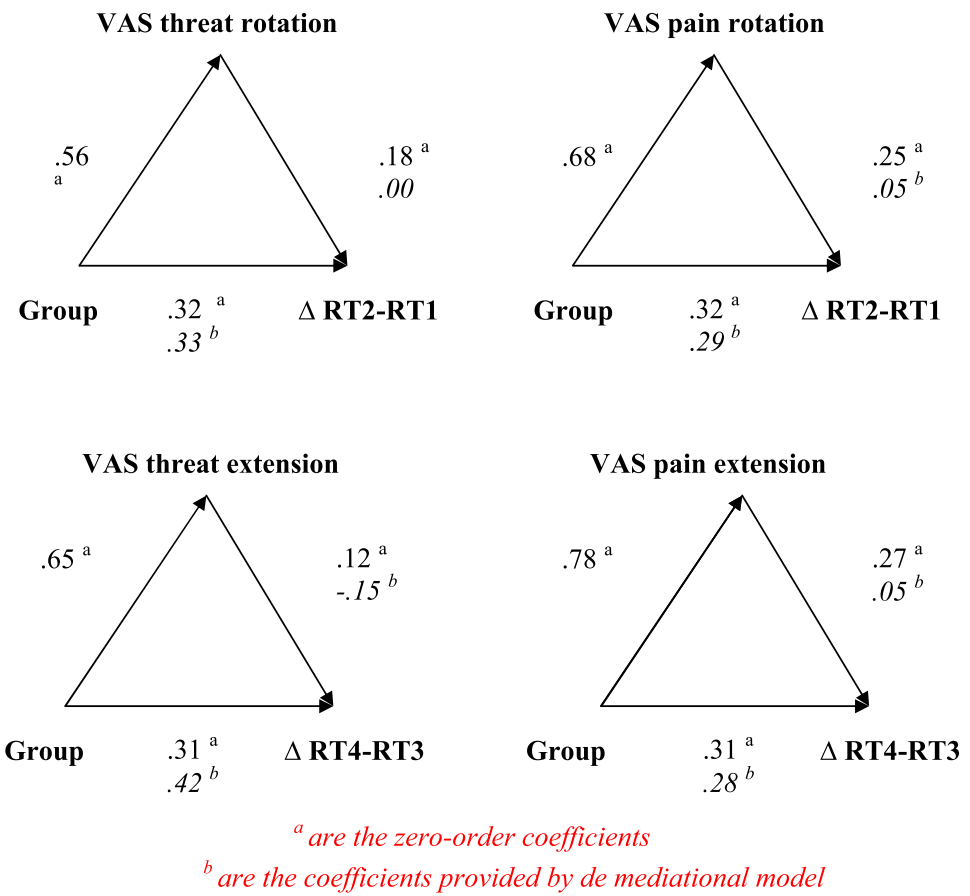

Fig. 3. Analysis of mediator variables. 
threat of the fixation significantly affected the degree of interference.

Our results reveal that activities that are perceived as threatening by patients demand attention and interfere with ongoing activity in patients with chronic whiplash syndrome. Previous studies have demonstrated that interference of performance by pain stimuli is present in both healthy subjects and in pain patients, and that this interference is increased by the threat value of the painful stimulus (Crombez et al., 1996, 1998a, 1999, 2002; Eccleston et al., 1997; Vancleef and Peters, 2006). In the present study we used a somatic stimulus with particular relevance for patients with chronic whiplash syndrome. Indeed the neck fixations were perceived as more threatening in patients than in healthy controls. The fixations were also scored as more painful by patients. Thus the increased interference in patients versus controls may be a function of the higher threat value of the fixation, the higher pain experience during the fixations or both. However, we could not identify threat value or pain experience as mediators of the performance decrement. A shortcoming of the study was that we assessed pain levels, threat value and unpleasantness retrospectively at the end of the experiment. This may have caused a recall bias. Future experiments should assess these potential mediators during and immediately after task performance.

We further predicted that participants with higher levels of pain-related fear and pain catastrophizing would show more interference than participants with lower levels of pain-related fear and catastrophizing (Eccleston et al., 1997; Peters et al., 2000; de Gier et al., 2003). However, we only found a significant effect of group. None of the other variables were significant in explaining attentional interference. Also, the effect of pain-related fear or catastrophic thinking about pain did not differ between patients and healthy controls. We did not find moderation effects. One possible explanation for the absence of effects of individual differences is the overall low level of pain catastrophizing in our sample of patients. Catastrophic thinking about pain in other samples of patients with whiplash injuries (Sullivan et al., 1998, 2002a,b) are almost twice as high as in the present study. A low level of pain catastrophizing may have reduced the power to detect significant effects. However, the scores of pain-related fear (TSK) are not in line with this argument. The TSK scores were in line with those of other samples of chronic pain patients (Peters et al., 2002; Nederhand et al., 2004). Furthermore, as was expected, pain-related fear and pain catastrophizing were highly interrelated in our sample.

A plausible explanation for our findings may be found in our choice of neck fixations as experimental stimulus. In previous studies, electrocutaneous stimuli, that were rated as mildly or moderately threatening, were used (Crombez et al., 1996, 1998a,b, 2002; Peters et al., 2002). In this study, patients rated the neck fixations as highly aversive in our sample. This may have limited the impact of individual differences in pain catastrophizing and pain-related fear. It is possible that all patients experienced the neck fixations as highly threatening and attentionally demanding. Indeed, according to some theoretical models (Mogg and Bradley, 1998; Eccleston and Crombez, 1999) everybody should attend to threat or pain when it is perceived as highly threatening. Future studies may choose less threatening stimuli that allow more variation between patients.

It should be noted that patients were also slower in their task performance during baseline conditions in comparison with the healthy controls. This parallels earlier findings of studies comparing reaction time performance between patients with pain complaints and healthy controls (Peters et al., 2000, 2002). In patients with chronic whiplash syndrome, this slowed-down performance may be a particular prominent feature. Indeed, patients suffering neck pain after a motor vehicle accident often complain of impairment in cognitive processes, such as divided attention (Radanov and Dvorak, 1996). A meta-analysis of cognitive disorders in these patients showed that they perform badly on various neuropsychological tests of attentional performance such as the PASAT (Paced Auditory Serial Task) or the Stroop Colour-Word Test (Kessels and Aleman, 2000). At present it is unknown whether these attentional deficits are the result of physical injuries or the result of interference by pain and threat value of perceived symptoms and disability. However, our study shows that this attentional deficit may be differentially affected by experiences that are perceived as threatening and painful by patients.

We may conclude that there is an apparent effect of incoming (threatening) stimuli on the current allocation of attention. Patients with chronic whiplash syndrome show attentional interference due to threatening and painful fixations of the neck, but the degree of interference is not associated with elevated levels of perceived pain or threat. In further research, a more in depth analysis should be made to establish whether the attentional interference is enhanced by the pain sensation (sensory characteristics) or by its threat value (affective characteristics), or by the interplay of both factors. Though we used the most common mediational analysis in psychological research (Baron and Kenny, 1986), this method lacks power and could be responsible for not finding small or moderate effects. Though it is very unlikely to make a Type I error with this method, it is most likely to miss real effects. This problem could be solved by increasing the sample size in further research (MacKinnon et al., 2002). Furthermore, the different components of attention could be investigated which would provide more detailed information on retarded task performance. Based on findings in the anxiety literature (Fox et al., 2001; Koster et al., 2004), it has 
been argued that three components of attention for pain can be distinguished (Van Damme et al., 2002b): (1) an initial temporary shift of attention towards the threatening stimulus (attentional shift), (2) a long captivation of attention by the threatening stimulus (engagement) and (3) releasing the attention from the threatening stimulus (disengagement). Recent studies have indicated that the attentional demand of pain is particularly related to difficulties disengaging attention from pain and signals of impending pain (Van Damme et al., 2002b, 2004a,b). However, this difficulty in disengaging from pain has only been demonstrated in healthy controls. In future research it would be interesting to investigate the different components of attention to relevant pain sensations in specific clinical populations.

\section{Acknowledgements}

This research was supported by Grant 940-31-071 from the Dutch Organisation for Scientific Research. The authors are grateful to the Belgian and Dutch Whiplash Patients Association for their help in contacting the patients and to Livit Orthopedics, Maastricht, The Netherlands, for manufacturing the modified somi-brace.

\section{References}

Baron RM, Kenny DA. The moderator-mediator variable distinction in social psychological research: conceptual, strategic, and statistical considerations. J Pers Soc Psychol 1986;51:1173-82.

Beekman ATF, van Limbeek J, Deeg DJH, Wouters L, van Tilburg W. Een screeningsinstrument voor depressie bij ouderen in de algemene bevolking: de bruikbaarheid van de Center for Epidemiologic Studies Depression Scale (CES-D). Tijdsch Gerontol Geriatr 1994;25:95-103.

Crombez G, Baeyens F, Eelen P. Sensory and temporal information about impending pain: the influence of predictability on pain. Behav Res Ther 1994;32:611-22.

Crombez G, Eccleston C, Baeyens F, Eelen P. The disruptive nature of pain: an experimental investigation. Behav Res Ther 1996;34:911-8.

Crombez G, Eccleston C, Baeyens F, Eelen P. Attentional disruption is enhanced by the threat of pain. Behav Res Ther 1998a;36:195-204.

Crombez G, Eccleston C, Baeyens F, Eelen P. When somatic information threatens, catastrophic thinking enhances attentional interference. Pain 1998b;75:187-98.

Crombez G, Eccleston C, Baeyens F, Van Houdenhove B, van den Broeck A. Attention to chronic pain is dependent upon painrelated fear. J Psychosom Res 1999;47:403-10.

Crombez G, Eccleston C, van den Broeck A, Van Houdenhove B, Goubert L. The effects of catastrophic thinking about pain on attentional interference by pain: no mediation of negative affectivity in healthy volunteers and in patients with low back pain. Pain Res Manag 2002;7:31-9.

Crombez G, Van Damme S, Eccleston C. Hypervigilance to pain: an experimental and clinical analysis. Pain 2005;116:4-7.

de Gier M, Peters ML, Vlaeyen JWS. Fear of pain, physical performance, and attentional processes in patients with fybromyalgia. Pain 2003;104:121-30.
Eccleston C, Crombez G, Aldrich S, Stannard C. Attention and somatic awareness in chronic pain. Pain 1997;72:209-15.

Eccleston C. Chronic pain and attention: a cognitive approach. Br J Clin Psychol 1994;33:535-47.

Eccleston C, Crombez G. Pain demands attention: a cognitive-affective model of the interruptive function of pain. Psychol Bull 1999;125:356-66.

Fox E, Russo R, Bowles R, Dutton K. Do threatening stimuli draw or hold attention in subclinical anxiety? J Exp Psychol 2001;130:681-700.

Goubert L, Crombez G, Van Damme S. The role of neuroticism, pain catastrophizing and pain-related fear in vigilance to pain: a structural equations approach. Pain 2004;107:234 41.

Helmerson Ackelman B, Lindgren U. Validity and reliability of a modified version of the neck disability index. J Rehab Med 2002;34:284-7.

Kessels RPC, Aleman A. Cognitieve stoornissen bij patiënten met het whiplashsyndroom. Een meta-analyse. Gedrag Gezond 2000;28:229-34

Koster EHW, Crombez G, Verschuere B, De Houwer J. Selective attention to threat in te dot probe paradigm: differentiating vigilance and difficulty to disengage. Behav Res Ther 2004;42:1183-92.

MacKinnon DP, Lockwood CM, Hoffman JM, West SG, Sheets V. A comparison of methods to test mediation and other intervening variable effects. Psychol Methods 2002;7:83-104.

McCracken LM. "Attention" to pain in persons with chronic pain: a behavioral approach. Behav Ther 1997;28:271-84.

McWilliams LA, Asmundson GJG. Assessing individual differences in attention to pain: psychometric properties of the Pain Vigilance and Awareness Questionnaire modified for a non-clinical sample. Pers Indiv Dif 2001;31:239-46.

Miller RP, Kori SH, Todd DD. The Tampa Scale.

Mogg K, Bradley BP. A cognitive-motivational analysis of anxiety. Behav Res Ther 1998;36:809-48.

Nederhand MJ, Ijzerman MJ, Hermens H, Zilvold G. Predictive value of fear avoidance in developing chronic neck pain disability: consequences for clinical decision making. Arch Phys Med Rehab 2004;85:496-501.

Peters ML, Vlaeyen JWS, Kunnen AMW. Is pain-related fear a predictor of somatosensory hypervigilance in chronic low back pain patients? Behav Res Ther 2002;40:85-103.

Peters ML, Vlaeyen JWS, van Drunen C. Do fybromyalgia patients display hypervigilance for innocuous somatosensory stimuli? Application of a body scanning reaction time paradigm. Pain 2000;86:283-92.

Price DD, McGrath PA, Rafii A, Buckingham B. The validation of visual analogue scales as ratio scale measures for chronic and experimental pain. Pain 1983;17:45-56.

Radanov BP, Dvorak J. Impaired cognitive functioning after whiplash injury of the cervical spine. Spine 1996;21:392-7.

Radloff LS. The CES-D scale: a self-report depression scale for research in the general population. Appl Psychol Meas 1977;1:385-401.

Ratcliff R. Methods for dealing with reaction time outliers. Psychol Bull 1993;114:510-32.

Roelofs J, Goubert L, Peters ML, Vlaeyen J, Crombez G. The Tampa Scale for Kinesiophobia: further examination of psychometric properties in patients with chronic low back pain and fibromyalgia. Eur J Pain 2004;8:495-502.

Roelofs J, Peters ML, McCracken L, Vlaeyen JWS. The pain vigilance and awareness questionnaire (PVAQ): further psychometric evaluation in fibromyalgia and other chronic pain syndromes. Pain 2003;101:299-306.

Sullivan MJL, Bishop SR, Pivik J. The Pain Catastrophizing Scale: development and validation. Psychol Assess 1995;7:524-32. 
Sullivan MJL, Stanish W, Sullivan ME, Tripp D. Differential predictors of pain and disability in patients with whiplash injuries. Pain Res Manag 2002a;7:68-74.

Sullivan MJL, Stanish W, Waite H, Sullivan M, Tripp DA. Catastrophizing, pain and disability in patients with soft-tissue injuries. Pain 1998;77:253-60.

Sullivan MJL, Sullivan ME, Adams HM. Stage of chronicity and cognitive correlates of Pain-related disability. Cogn Behav Ther 2002b;31:111-8.

Swinkels-Meewisse EJCM, Swinkels RAHM, Verbeek ALM, Vlaeyen JWS, Oostendorp RAB. Psychometric properties of the Tampa Scale for Kinesiophobia and the fear-avoidance beliefs questionnaire in acute low back pain. Man Ther 2003;8:29-36.

Van Damme S, Crombez G, Bijttebier P, Goubert L, Van Houdenhove B. A confirmatory factor analysis of the Pain Catastrophizing Scale: invariant factor structure across clinical and non-clinical populations. Pain 2002a;96:319-24.

Van Damme S, Crombez G, Eccleston C. Retarded disengagement from pain cues: the effects of pain catastrophizing and pain expectancy. Pain 2002b;100:111-8.
Van Damme S, Crombez G, Eccleston C. Disengagement from pain: the role of catastrophic thinking about pain. Pain 2004a;107:70-6.

Van Damme S, Crombez G, Eccleston C. The anticipation of pain modulates spatial attention : evidence of pain specificity in high pain catastrophizers. Pain 2004b;111:392-9.

Vancleef LMG, Peters ML. Pain Catastrophising, but not injury/ilness sensitivity or anxiety sensitivity enhances attentional interference in pain. J Pain 2006;7:23-30.

Vernon H. Correlations among ratings of pain, disability and impairment in chronic whiplash-associated disorders. Pain Res Manag 1997;2:207-13.

Vlaeyen JWS, Kole-Snijders AMJ, Boeren RGB, van Eek H. Fear of movement/(re)injury in chronic low back pain and its relation to behavioral performance. Pain 1995a;62:363-72.

Vlaeyen JWS, Kole-Snijders AMJ, Rotteveel AM, Ruesink R, Heuts PHTG. The role of fear of movement/(re)injury in pain disability. J Occup Rehabil 1995b;5:235-52.

Vlaeyen JWS, Linton SJ. Fear-avoidance and its consequences in chronic musculoskeletal pain: a state of the art. Pain 2000;85:317-32. 